\title{
Antagonismo NMDA en el tratamiento de la cefalea en racimos
}

\author{
M. L. Padilla del Rey¹, M. Benítez Jiménez², J. F. Canuel${ }^{3}$ y C. Díaz-Alejo Marchante ${ }^{4}$
}

${ }^{1}$ Médico especialista en Anestesiología y Reanimación, Unidad del Dolor, Servicio de Anestesiología, Reanimación y Terapéutica del Dolor, Hospital General Universitario José María Morales Meseguer, Murcia, España. ${ }^{2}$ Médico residente en Anestesiología y Reanimación, Servicio de Anestesiología, Reanimación y Terapéutica del Dolor, Hospital General Universitario José María Morales Meseguer, Murcia. España. ${ }^{3}$ Médico especialista en Anestesiología y Reanimación, Unidad del Dolor, CHU de Québec, Université Laval, Québec, Canadá. ${ }^{4}$ Médico especialista en Anestesiología y Reanimación, Unidad del Dolor, Servicio de Anestesiología, Reanimación y Terapéutica del Dolor, Hospital Universitario del Vinalopó, Alicante. España

\section{ABSTRACT}

Standard treatment for cluster headache consists of abortive treatment with oxygen, triptans, ergot alkaloids and/or topical nasal local anesthetic during acute episodes and preventive treatment such as steroid injections, calcium channel blockers and lithium. Although the exact pathophysiology of cluster headache is not well understood, reduced serum levels of kynurenine metabolites with anti-NMDA ( $N$-methyl-D-aspartate) properties have been demonstrated. Ketamine and magnesium, which both have potent anti-NMDA receptor activity, have been used in multiple refractory pain syndromes. We describe a case of cluster headache that was non-responsive to standard therapy and treated effectively with intravenous infusion of magnesium and ketamine.

Key words: NMDA, ketamine, magnesium sulfate, cluster headache.

\section{RESUMEN}

El tratamiento estándar de la cefalea en racimos consiste en un tratamiento abortivo con oxígeno, triptanes, alcaloides ergóticos y/o anestésico local nasal tópico durante los episodios agudos y un tratamiento preventivo, como infiltraciones con esteroides, antagonistas de los canales del calcio y litio. Aunque la fisiopatología exacta de la cefalea en racimos no se conoce bien, se han demostrado niveles reducidos de metabolitos de quinurenina, los cuales gozan de propiedades anti-NMDA (N-metil-D-aspartato). La ketamina y el magnesio, que tienen una potente actividad antagonista NMDA, se han usado en múltiples síndromes de dolor refractario. Describimos un caso de cefalea en racimos que no respondió al tratamiento estándar y se trató de forma efectiva con infusión intravenosa de magnesio y ketamina.

Palabras clave: NMDA, ketamina, sulfato de magnesio, cefalea en racimos.

Esta entidad se caracteriza por la aparición cíclica de dolor unilateral orbitario, supraorbitario y/o temporal, breve e intenso, y que se acompaña de inquietud y/o agitación y/o al menos uno de los siguientes síntomas o signos homolaterales: hiperemia conjuntival y/o lagrimeo, congestión nasal y/o rinorrea, sudoración frontal y/o facial, miosis y/o ptosis, edema palpebral. Los episodios duran entre 15 y 180 minutos y recurren con frecuencia variable, entre un ataque cada

Recibido: 30-09-2018

Aceptado: 25-03-2019

Padilla del Rey ML, Benítez Jiménez M, Canuel JF, Díaz-Alejo Marchante C. Antagonismo NMDA en el tratamiento de la cefalea en racimos. Rev Soc Esp Dolor 2019;26[4]:247-250.
Correspondencia: María Luz Padilla del Rey mariluzpadilladelrey@gmail.com 
dos días y ocho ataques diarios. De acuerdo con su periodicidad, puede clasificarse en episódica o crónica, según si los periodos de remisión entre los ataques ocurridos en un año son mayores o menores de tres meses [1].

La prevalencia de la CR es del 0,1-0,4\% de la población general y la edad de comienzo suele estar comprendida entre los 20 y los 40 años. Por motivos que se desconocen, en general, los varones se ven afectados tres veces más que las mujeres; no obstante, estudios epidemiológicos recientes indican que esta diferencia es cada vez menor [2]. Algunas investigaciones sugieren que en el $5 \%$ de los casos la CR puede estar transmitida de forma autosómica dominante [1].

La última actualización de la guía para el tratamiento de la CR de la American Headache Society (AHS) (3) recomienda el empleo de oxigenoterapia al 100\%, sumatriptán subcutáneo y/o zolmitriptán intranasal en las crisis. Para los pacientes que no responden ni toleran esta medicación de primera línea, las opciones alternativas incluyen sumatriptán intranasal, zolmitriptán oral, estimulación del ganglio esfenopalatino, anestésico tópico nasal y octreotida subcutánea (Tabla I).

Los corticoides son considerados como tratamiento profiláctico de transición, debido a su corta latencia y duración del efecto, contemplándose como una terapia puente mientras la medicación de mantenimiento es escalada hasta alcanzar dosis máximas y/o eficaces. La inyección subcutánea suboccipital o bloqueo del nervio occipital mayor ipsilateral al dolor con corticoides goza del nivel más alto de recomendación de la AHS dentro de las opciones terapéuticas profilácticas de la CR.

Como tratamiento preventivo a largo plazo existe evidencia positiva sobre la aplicación de una solución, no disponible en España, de civamida (zucapsaicina) intranasal y sobre la administración de carbonato de litio, verapamilo, warfarina y melatonina (Tabla II).
Otras alternativas que han demostrado eficacia pero que no cumplieron los criterios de inclusión y exclusión para elaborar la revisión sistemática de la AHS son las siguientes: metisergida, metilergonovina, flunarizina, topiramato, gabapentina, baclofeno, clonidina, pizotifeno, histamina, kudzu, ácido 2-bromo-lisérgico, tratamiento hormonal como testosterona y clomifeno, inyecciones de toxina botulínica y bloqueo y/o radiofrecuencia del ganglio esfenopalatino (3).

Actualmente, en aquellos casos rebeldes al tratamiento estándar, la ketamina parece ser un fármaco efectivo ya que bloquea el receptor glutamatérgico N-metil-D-aspartato (NMDA). Además, este efecto analgésico podría verse potenciado gracias a la combinación con sulfato de magnesio, que actúa bloqueando la misma vía [4].

\section{CASO CLÍNICO}

Mujer de 65 años, con historia previa de CR episódica, fumadora de 10 paquetes/año y sin otros antecedentes médico-quirúrgicos de interés, que fue remitida a la Unidad del Dolor por Neurología. En el momento de ser valorada por nosotros, la paciente presentaba un brote de CR de 2 meses de evolución con una media de seis crisis diarias de predominio nocturno. Al inicio del cuadro había sido evaluada por su neurólogo, que le había pautado tanto medicación abortiva [oxigenoterapia al $100 \%$, zolmitriptán intranasal, diazepam) como profiláctica (verapamilo y topiramato). Se reajustó el tratamiento y se añadió: lidocaína intranasal al $4 \%$ aplicada con una torunda colocada lo más próxima al cornete medio, 6 mg de sumatriptán subcutáneo para el control de las crisis, $1 \mathrm{mg} / \mathrm{kg} / \mathrm{día}$ de prednisona con posterior pauta descendente, $25 \mathrm{mg} /$ día de amitriptilina y 2 mg/día de melatonina para su prevención. Además, se le realizaron tres infiltraciones (la primera por parte del Servicio de Neurología y las dos siguientes, ecoguiadas, por parte de la Unidad de Dolor] del

TABLA I

EVIDENCIA Y NIVELES DE RECOMENDACIÓN PARA EL TRATAMIENTO AGUDO DE LA CEFALEA EN RACIMOS SEGÚN LA AMERICAN HEADACHE SOCIETY

\begin{tabular}{|c|l|l|l|}
\hline \multicolumn{2}{|c|}{ POSITIVA } & \multicolumn{2}{|c|}{ INSUFIENTE } \\
\hline Nivel de recomendación & \multicolumn{1}{|c|}{ Fármaco } & Nivel de recomendación & \multicolumn{1}{c|}{ Fármaco } \\
\hline $\begin{array}{l}\text { A: establecido como } \\
\text { eficaz }\end{array}$ & $\begin{array}{l}\text { Sumatriptán (subcutáneo) } \\
\text { Zolmitriptán (aerosol } \\
\text { nasal) } \\
\text { Oxígeno }\end{array}$ & & \\
\cline { 1 - 2 } B: probablemente eficaz & $\begin{array}{l}\text { Sumatriptán (aerosol } \\
\text { nasal) } \\
\text { Zolmitriptán (oral) } \\
\text { Estimulación del ganglio } \\
\text { esfenopalatino }\end{array}$ & $\begin{array}{l}\text { U: evidencia insuficiente } \\
\text { para establecer una } \\
\text { recomendación }\end{array}$ & $\begin{array}{l}\text { Dihidroergotamina } \\
\text { (aerosol nasal) } \\
\text { Somatostatina } \\
\text { Prednisona }\end{array}$ \\
\hline C: posiblemente eficaz & $\begin{array}{l}\text { Cocaína/lidocaína } \\
\text { (aerosol nasal) } \\
\text { Octreotida (subcutánea) }\end{array}$ & & \\
\hline
\end{tabular}

Traducida y adaptada de Robbins et al. ${ }^{3}$ 
TABLA II

EVIDENCIA Y NIVELES DE RECOMENDACIÓN PARA EL TRATAMIENTO PROFILÁCTICO DE LA CEFALEA EN RACIMOS SEGÚN LA AMERICAN HEADACHE SOCIETY

\begin{tabular}{|c|c|c|c|c|c|}
\hline \multicolumn{2}{|c|}{ POSITIVA } & \multicolumn{2}{|c|}{ INSUFICIENTE } & \multicolumn{2}{|c|}{ NEGATIVA } \\
\hline $\begin{array}{c}\text { Nivel de } \\
\text { recomendación }\end{array}$ & Fármaco & $\begin{array}{c}\text { Nivel de } \\
\text { recomendación }\end{array}$ & Fármaco & $\begin{array}{c}\text { Nivel de } \\
\text { recomendación }\end{array}$ & Fármaco \\
\hline $\begin{array}{l}\text { A: establecido } \\
\text { como eficaz }\end{array}$ & $\begin{array}{l}\text { Inyección } \\
\text { suboccipital de } \\
\text { esteroides }\end{array}$ & \multirow{3}{*}{$\begin{array}{l}\text { U: evidencia } \\
\text { insuficiente para } \\
\text { establecer una } \\
\text { recomendación }\end{array}$} & \multirow{3}{*}{$\begin{array}{l}\text { Frovatriptán } \\
\text { Capsaicina } \\
\text { (crema } \\
\text { intranasal) } \\
\text { Tolerancia a } \\
\text { nitratos } \\
\text { Prednisona }\end{array}$} & $\begin{array}{l}\text { B: probablemente } \\
\text { ineficaz }\end{array}$ & $\begin{array}{l}\text { Valproato sódico } \\
\text { Sumatriptán } \\
\text { Estimulación } \\
\text { cerebral } \\
\text { profunda }\end{array}$ \\
\hline $\begin{array}{l}\text { B: probablemente } \\
\text { eficaz }\end{array}$ & $\begin{array}{l}\text { Civamida } \\
\text { (aerosol nasal) }\end{array}$ & & & & \multirow{2}{*}{$\begin{array}{l}\text { Cimetidina/ } \\
\text { clorfeniramina } \\
\text { Misoprostol } \\
\text { Oxígeno } \\
\text { hiperbárico } \\
\text { Candesartán }\end{array}$} \\
\hline $\begin{array}{l}\text { C: posiblemente } \\
\text { eficaz }\end{array}$ & $\begin{array}{l}\text { Litio } \\
\text { Verapamilo } \\
\text { Warfarina } \\
\text { Melatonina }\end{array}$ & & & $\begin{array}{l}\text { C: posiblemente } \\
\text { ineficaz }\end{array}$ & \\
\hline
\end{tabular}

Traducida y adaptada de Robbins et al. ${ }^{3}$

nervio occipital mayor con levobupivacaína al 0,25 \% y $20 \mathrm{mg}$ de triamcinolona acetónido (el máximo periodo de remisión fue de 6 días, tras la segunda infiltración, en la que se infiltró también el nervio occipital menor], precediéndose la tercera, además, de una radiofrecuencia pulsada, a 45 voltios durante 6 minutos, de dicho nervio.

Transcurridos 4 meses desde el comienzo del episodio y ante la no mejoría clínica y el deseo expreso de la paciente de intentar evitar otros procedimientos intervencionistas, se decidió realizar, (previo consentimiento informado y bajo monitorización estándar [pulsioximetría, presión arterial no invasiva, electrocardiograma] y oxigenoterapia con gafas nasales a $3 \mathrm{l} / \mathrm{min}$ con capnografía, previa administración de 0,1 mg/kg de midazolam en bolo lento durante 5 minutos] una perfusión de $1 \mathrm{mg} / \mathrm{kg}$ de ketamina y $3 \mathrm{~g}$ de sulfato de magnesio en un suero fisiológico de $100 \mathrm{ml}$ durante 60 minutos, que aconteció sin incidencias. Después de este tratamiento las crisis cedieron durante 3 días, tras los cuales se reiniciaron. En un principio fueron de menor intensidad, pero terminaron exacerbándose, por lo que se decidió repetir la perfusión al mes. Tras la misma tuvieron lugar dos crisis en total, que se controlaron con oxigenoterapia y lidocaína intranasal. Se decidió proceder a una tercera y última perfusión 4 semanas después de la segunda.

Actualmente, a los 6 meses de la última perfusión, la paciente refiere que ha abandonado el hábito tabáquico, únicamente toma $80 \mathrm{mg} /$ día de verapamilo y $2 \mathrm{mg} /$ día de melatonina como tratamiento profiláctico y, en los momentos en los que ella percibe que se puede desencadenar una crisis (momentos de estrés, ansiedad, agitación, etc.) o comienza con lo que parecen pródromos de un episodio de CR (la paciente lo describe "como si el ojo fuera empujado a salir de su órbita"], se autoadministra oxígeno y lidocaína intranasal tópica, manteniéndose hasta la fecha libre de crisis.

\section{DISCUSIÓN}

La CR, cefalea trigémino-autonómica más frecuente (3), es considerada una de las más intensas e invalidantes dentro del grupo de las cefaleas primarias, y aunque se dispone de tratamientos sintomáticos y preventivos eficaces, estos pueden no ser suficientes en casos rebeldes, tal y como ocurrió en el caso que presentamos.

Un dato relevante en esta patología es que en torno al $85 \%$ de los pacientes son fumadores crónicos y, aunque dejar de fumar no parece tener ningún efecto sobre la enfermedad una vez establecida, el hábito tabáquico puede ser un factor de riesgo para su desarrollo, posiblemente sobre la base de una predisposición genética (5). Por otro lado, sí parece haber una relación entre ser fumador y formas más intensas de CR (6). Por consiguiente, basándonos en la bibliografía consultada, podríamos inferir que la mejoría sintomatológica en la paciente se debe principalmente al tratamiento médico instaurado y no al abandono del hábito tabáquico, sin poder descartar, por supuesto, que esta última medida no contribuya a la magnífica evolución del cuadro.

Es sabido que la administración de ketamina, debido a su acción anti-NMDA y a sus probables efectos antiinflamatorios y de potenciación de las vías inhibitorias descendentes, entre otros, puede ser efectiva en el tratamiento del dolor crónico, incluyendo la cefalea refractaria a tratamiento [4]. Además del alivio del dolor, una sola infusión de ketamina parece ser efectiva para reducir rápidamente la ideación suicida, que puede ser un problema relevante en pacientes con CR. Asimismo, la combinación con sulfato de magnesio produciría un efecto analgésico sinérgico (7). Tomando estas premisas como base, y al igual que procedió el grupo de Moisset et al. (8), pero con dosis (1 mg/kg de ketamina en lugar de $0,5 \mathrm{mg} / \mathrm{kg}$ ) e intervalos entre perfusiones ( 1 mes lugar de 8 semanas) diferentes, se decidió instaurar el tratamiento con ketamina y sulfato 
Rev. Soc. Esp. del Dolor, Vol. 26, N. 4, Julio-Agosto 2019

de magnesio intravenoso, tras lo que se obtuvo buena respuesta, cediendo las crisis de CR hasta el momento actual. Investigaciones recientes demuestran niveles reducidos de ácido quinurénico (antagonista del receptor NMDA) en pacientes con CR, lo que refuerza la hipótesis de la supuesta hiperactividad de los receptores NMDA en esta patología [9]. No obstante, aún son necesarios estudios para poder determinar la eficacia y seguridad de este tratamiento en pacientes con CR.

Actualmente se están analizando nuevas opciones de tratamiento con resultados prometedores (10). Las líneas de investigación tienen el punto de mira en la terapia con anticuerpos monoclonales, que actuarian bloqueando el receptor CGRP (péptido relacionado con el gen de la calcitonina) y otros receptores implicados en la fisiopatología de la CR. Además, se estudia el uso de nuevos dispositivos para administración de medicamentos ya aprobados (como el parche transdérmico de zolmitriptán con microagujas (11)], nuevas formas de neuroestimulación (por ejemplo, estimulación no invasiva del nervio vago (12)] y otras líneas que podrían ser el futuro en el tratamiento de la CR.

\section{CONFLICTO DE INTERESES}

Los autores declaran no tener ningún conflicto de intereses.

\section{BIBLIOGRAFÍA}

1. Headache Classification Committee of the International Headache Society (IHS). The International Classification of Headache Disorders, 3rd edition. Cephalalgia. 2018;38(1):1-211.

2. Black DF, Swanson JW, Stang PE. Decreasing incidence of cluster headache: a population-bases study in Olmsted county, Minnesota. Headache. 2005;45:220-3.

3. Robbins MS, Starling AJ, Pringsheim TM, Becker WJ, Schwedt TJ. Treatment of cluster headache: The American Headache Society Evidence-Based Guidelines. Headache. 2016;56:1093-106.

4. Liu HT, Hollmann MW, Liu WH, Hoenemann CW, Durieux ME. Modulation of NMDA receptor function by ketamine and magnesium: Part I. Anesth Analg. 2001;92:1173-81.

5. Rozen TD. Cluster headache as the result of secondhand cigarette smoke exposure during childhood. Headache. 2010;50(1):130-2.

6. Ferrari A, Zappaterra M, Righi F, Ciccarese M, Tiraferri I, Pini LA, et al. Impact of continuing or quitting smoking on episodic cluster headache: a pilot survey. J Headache Pain. 2013;14(1):48.

7. Mion G, Villevieille T. Ketamine pharmacology: an update (pharmacodynamics and molecular aspects, recent findings). CNS Neurosci Ther. 2013;19(6):370-80.

8. Moisset X, Clavelou P, Lauxerois M, Dallel R, Picard P. ketamine infusion combined with magnesium as a therapy for intractable chronic cluster headache: report of two cases. Headache. 2017;57(8):1261-4.

9. Curto M, Lionetto L, Negro A, Capi M, Perugino F, Fazio F, et al. Altered serum levels of kynurenine metabolites in patients affected by cluster headache. J Headache Pain. 2015;17:27.

10. Vikelis M, Konstantinos C, Rapoport AM. A new era in headache treatment. Neurol Sci. 2018;39 Suppl 1:47-58.

11. Uppuluri CT, Devineni J, Han T, Nayak A, Nair KJ, Whiteside $\mathrm{BR}$, et al. Microneedle-assisted transdermal delivery of Zolmitriptan: effect of microneedle geometry, in vitro permeation experiments, scaling analyses and numerical simulations. Drug Dev Ind Pharm. 2017;43(8):1292-303.

12. Yuan $\mathrm{H}$, Silberstein $\mathrm{SD}$. Vagus nerve stimulation and headache. Headache. 2017; 57 Suppl 1:29-33. 